\title{
EM BUSCA DE ALTERNATIVAS NA EDUCAÇÃO EM IES: AULAS REMOTAS, SÍNCRONAS E ASSÍNCRONAS
} Sōnia Maria Nogueira*

(iD) https://orcid.org/0000-0003-4005-4508 Gilberto Freire de Santana*

(D) https://orcid.org/0000-0002-3018-3018

Como citar este artigo: NOGUEIRA, S. M.; SANTANA, G. F. de. Em busca de alternativas na educação em IES: aulas remotas, síncronas e assíncronas. Todas as Letras - Revista de Lingua e Literatura, São Paulo, v. 23, n. 2, p. 1-14, maio/ago. 2021. DOI 10.5935/1980-6914/eLETDO2114606

Submissão: junho de 2021. Aceite: junho de 2021.

Resumo: Este artigo propõe reflexões sobre o percurso do ensino de língua portuguesa e suas literaturas realizado no período de pandemia em instituição de ensino superior (IES) da rede pública. Ele objetiva apresentar a trajetória de um curso de graduação em Letras e um de mestrado em Letras, a partir de alguns atos normativos para enfrentamento da pandemia da Covid-19 no Maranhão. Essa discussão é acompanhada de breve estudo de caso que visa ilustrar considerações teórico-metodológicas apresentadas. Assim, aponta-se como o processo de ensino busca práticas inovadoras, a exemplo de metodologias ativas, na difusão do conhecimento sobre a linguagem e literatura.

Palavras-chave: Língua Portuguesa e Literatura. Pandemia Covid-19. Metodologias ativas. Maranhão. Ensino remoto.

\footnotetext{
* Universidade Estadual da Região Tocantina do Maranhão (Uemasul), Imperatriz, MA, Brasil. E-mail: sonianogueira@uemasul.edu.br

** Uemasul, Imperatriz, MA, Brasil. E-mail: gilbertosantana@uemasul.edu.br
} 


\section{CONSIDERAÇÕES INICIAIS}

$\boldsymbol{E}$

ste artigo propõe reflexões sobre o percurso do ensino de língua portuguesa e suas literaturas realizado no período de pandemia em instituição de ensino superior (IES) da rede pública. Ele objetiva apresentar a trajetória de um curso de graduação em Letras e de um curso de mestrado em Letras, a partir de alguns atos normativos para enfrentamento da pandemia da Covid-19 no Maranhão. Essa discussão é acompanhada de breve estudo de caso que visa ilustrar considerações teórico-metodológicas apresentadas. Assim, aponta-se como o processo de ensino busca práticas inovadoras na difusão do conhecimento sobre a linguagem e literatura. Nesse cenário, verifica-se o comprometimento da IES na busca, incessante, por incentivar/estimular o discente a questionar saberes já estabelecidos, (re)conhecer memória, cultura e identidade, para adaptá-los aos novos tempos e, assim, atuar de forma transformadora na sociedade de que faz parte - comunidades indigenas, campesinas, quilombolas, ribeirinhas, entre outras -, propondo o diálogo constante da IES com a comunidade.

Para tanto, conta com as seções: "No interior de uma universidade em tempos de pandemia"; "Na urgência de ações, atos e normas para enfrentamento da pandemia da Covid-19 no Maranhão"; "Encontrando alternativas na educação: aulas remotas, sincronas e assíncronas" e "Considerações finais".

\section{NO INTERIOR DE UMA UNIVERSIDADE EM TEMPOS DE PANDEMIA}

A Universidade Estadual da Região Tocantina do Maranhão (Uemasul) é uma IES pública estadual brasileira, criada em novembro de 2016, autarquia, vinculada à Secretaria de Estado da Ciência, Tecnologia e Inovação (Secti), do Maranhão, subordinada ao governo estadual, no que se refere aos subsídios para a sua operação (MARANHÃO, 2016a). Localizada em um território do Maranhão que forma um triângulo com os estados do Tocantins e do Pará, a área de atuação territorial da Uemasul abrange 22 municípios. Os cursos de graduação da Uemasul são, predominantemente, da área pedagógica (11 cursos de licenciatura), particularmente o curso de Letras - Língua Portuguesa e Literaturas contribui com a enorme demanda de professores da região.

Essa IES se arraigou e se expandiu a partir da cidade de Imperatriz, no Maranhão, quando, em 1973, inicialmente, foi criada a Fundação Universidade de Imperatriz (Fuim). Após alterações, foi criada a Federação das Escolas Superiores do Maranhão (Fesm), para coordenar e integrar os estabelecimentos isolados do sistema educacional superior do Maranhão. A Fesm foi constituída por quatro unidades de ensino superior, entre elas, a Faculdade de Educação de Imperatriz. Posteriormente, em 1985, foi autorizada a planificação dos cursos da Unidade de Estudos de Educação de Imperatriz (Ueei). A Universidade Estadual do Maranhão (Uema) foi criada pela Lei $n^{\circ} 4.400$, de 30 de dezembro de 1981 (MARANHÃO, 1981), com sede e foro na cidade de São Luís, no estado do Maranhão, e aditada pela Lei $n^{\circ}$ 5.921, de 15 de março de 1994 (MARANHÃO, 1994). A partir desse ato normativo, a Ueei passou a ser denominada Centro de Estudos Superiores de Imperatriz (Cesi). Nesse sentido, como parte integrante do projeto de regionalização da educação superior do estado do Maranhão, em se- 
tembro de 2016, o Poder Executivo do estado enviou à Assembleia Legislativa do Estado do Maranhão (Alema) o Projeto de Lei n 181/2016 (MARANHÃO, 2016b), que propunha a criação da Uemasul, e a Lei no 10.525 (MARANHÃO, 2016a) cria a Uemasul. A universidade, por sua vinculação histórica às licenciaturas, desde a sua criação inicial como campus da Uema, é a principal instituição de ensino superior da Região Tocantina do Maranhão na formação de professores.

Convém indicar que a Lei de Diretrizes e Bases da Educação Nacional, Lei $\mathrm{n}^{\circ}$ 9.394, de 20 de dezembro de 1996 (BRASIL, 1996), trouxe em seu bojo mudanças significativas com relação à formação do profissional docente. Assim, de acordo com o artigo 53, em seu caput e inciso $2^{\circ}$, "no exercício de sua autonomia, são asseguradas às universidades, sem prejuízo de outras, as seguintes atribuições: II - fixar os currículos dos seus cursos e programas, observadas as diretrizes gerais pertinentes". A partir desse dispositivo legal, várias ações foram implementadas pelo Ministério da Educação (MEC) na busca por um sistema de ensino que atendesse às exigências dessa lei. Nessa perspectiva, a universidade constitui-se de um espaço capaz de atender às necessidades educativas e tecnológicas da sociedade, consequentemente, um local primordial para desenvolver um trabalho (inter/trans)disciplinar que contemple a formação específica, pedagógica e humanística. O intuito deve privilegiar a formação de profissionais capacitados para o ensino, a pesquisa, a extensão e a inovação, de modo que haja engajamento entre universidade e sociedade, assim como intervenção na realidade social.

Nesse cenário, o curso de licenciatura em Letras - Lingua Portuguesa e Literaturas, do Centro de Ciências Humanas, Sociais e Letras (CCHSL), da Uemasul, apresenta-se com uma base formada por conhecimentos linguísticos, literários e culturais que se inter-relacionam com o processo educativo, concebendo a linguagem como uma ferramenta de comunicação e de participação social, promovendo o desenvolvimento de cidadãos tanto críticos quanto reflexivos. Especificamente, o curso propõe-se a formar e a preparar docentes que tenham um efetivo compromisso com a transformação da educação básica regional e brasileira, para corresponder aos anseios da sociedade por um país democrático, preservando os direitos fundamentais, tais quais a liberdade e a pluralidade de ideias, que se manifestam no cultivo da reflexão filosófica, das letras e artes e do conhecimento científico, conforme determina a Base Nacional Comum Curricular (BNCC) (BRASIL, 2018). Assim, valoriza a reflexão crítica e sistemática dos saberes, sobretudo, científicos e, no trabalho intelectual, que diz respeito a tudo que concerne à cultura da sociedade, particularmente, a regional. Busca, consequentemente, incentivar/estimular o discente a questionar saberes já estabelecidos, (re)conhecer a memória, cultura e identidade, a fim de adaptá-los aos novos tempos, e atuar de forma transformadora na sociedade de que faz parte comunidades indigenas, campesinas, quilombolas, ribeirinhas, entre outras -, fazendo menção ao projeto pedagógico de curso (PPC), do curso de Letras - Língua Portuguesa e Literaturas em construção para fins de recredenciamento.

A politica institucional de pós-graduação da Uemasul, conforme o seu Plano de Desenvolvimento Institucional (PDI) (MARANHÃO, 2017), propõe levar a termo a expansão continuada e o fortalecimento dos cursos lato sensu e stricto sensu. E uma de suas metas é a inserção de novas redes de mestrado, a exemplo de Linguística, Letras e Artes entre as grandes áreas a serem privilegiadas. 
No tocante ao programa de pós-graduação stricto sensu, a Uemasul teve seu primeiro - o Programa de Pós-Graduação em Letras (PPGLe) - aprovado no início de 2019, modalidade profissional, com área de concentração em Linguagem e Literatura, e duas linhas de pesquisa: 1. Linguagem, Memória e Ensino, e 2. Literatura, Diálogos e Saberes, que concentram distintos estudos que concorrem para a melhoria do ensino e para o desenvolvimento da pesquisa e, por consequência, para a educação da região, do estado e do país. Esse recém-criado programa de pós-graduação tem entre seus objetivos o de trazer à tona questões/propostas, de modo que desenvolvam estudos e conhecimentos que repercutam na qualidade de ensino das escolas de educação básica da região e do estado do Maranhão. O programa conta com professores dos campi Imperatriz, Açailândia e Estreito (Uemasul) e de Balsas (Uema), e já realizou dois processos seletivos. Para a seleção da primeira turma, em 2019, além dos egressos da Uemasul, houve candidatos oriundos de outras IES (por exemplo, Universidade Federal do Maranhão [Ufma] e Uema) e de diversas cidades do Maranhão. Para o primeiro edital, houve 63 inscrições, que resultaram em 17 alunos aprovados e matriculados. As atividades acadêmicas do curso foram iniciadas em outubro de 2019.

\section{NA URGÊNCIA DE AÇÕES, ATOS E NORMAS PARA ENFRENTAMENTO DA PANDEMIA dA Covid-19 No MARANHÃo}

Em março de 2020, o mundo foi surpreendido com a pandemia, em decorrência da Covid-19. O governo brasileiro reconheceu e declarou emergência em saúde pública de importância nacional, a fim de adotar medidas proporcionais e restritas aos riscos iminentes, em março de 2020 (BRASIL, 2020a). O governador do estado do Maranhão elaborou o Plano de Contingência com medidas de prevenção, contenção de riscos e danos à saúde pública, considerando evitar a disseminação da doença em âmbito estadual (MARANHÃO, 2020a). Neste ato, as aulas presenciais em todas as unidades de ensino da rede estadual de educação, nas instituições de ensino das redes municipais, inclusive nas escolas e instituições de ensino superior da rede privada localizadas no estado do Maranhão, foram suspensas por 15 dias.

Mediante esse cenário, em observância aos decretos do estado do Maranhão, a Uemasul também providenciou seus atos normativos com orientações relativas às medidas de enfrentamento à pandemia. As escalas de trabalho passaram a ser presenciais e remotas, com rodizio entre os servidores das unidades, a fim de permanecer o atendimento administrativo e considerar as demais medidas de segurança da saúde. E a implementação de tecnologias digitais da informação e comunicação (Tdic) para as reuniões de trabalho que exigissem encontros de servidores, assim como ficaram mantidos canais para atendimento remoto, disponíveis no portal da universidade. Especificamente, os pesquisadores puderam dar continuidade aos projetos com acesso às dependências da universidade mediante autorização expressa do respectivo centro de ciências vinculado (MARANHÃO, 2021a).

Convém ser esclarecido que os serviços de tecnologia digital de informação e comunicação, considerados de caráter essencial para suporte ao ensino remoto, não foram suspensos (MARANHÃO, 2021c). A suspensão das atividades presen- 
ciais, tanto de natureza administrativa quanto acadêmica nos campi da Uemasul, foi estabelecida, inicialmente, no periodo de 5 de março a 4 de abril de 2021 (MARANHÃO, 2021d). Logo após, de 6 a 11 de abril de 2021, pôde-se observar a implantação de jornada de atividade em modo presencial e teletrabalho concomitante, denominada sistema híbrido (MARANHÃO, 2021e).

Em agosto de 2021, novas diretrizes e normas para o ensino emergencial remoto foram estabelecidas com a alteração do calendário acadêmico de 2020, seguindo recomendações estabelecidas para a reorganização do calendário escolar e da possibilidade de cômputo de atividades não presenciais para fins de cumprimento da carga horária minima anual, conforme o Parecer CNE/CP n 5/2020 (BRASIL, 2020b). Assim, algumas disposições previam

[...] a diversificação de metodologias e ferramentas pedagógicas não presenciais, mediadas ou não por tecnologias digitais de comunicação e informação, considerando as fragilidades e desigualdades estruturais da sociedade brasileira agravados [sic] pela pandemia, visando à minimização dos reflexos das desigualdades, da retenção e da evasão acadêmica (MARANHÃO, 2020b).

Verifica-se, também, nesse dispositivo "a substituição de componentes curriculares que não podem ser realizados de forma não presencial por outros componentes teóricos, enquanto não se retornar às atividades presenciais" (MARANHÃO, 2020b). Diante desse cenário, foi instituído o ensino ministrado em blocos, cada um constituído por até $50 \%$ dos componentes curriculares ofertados em cada turma.

Outro ato normativo foi a aprovação do calendário acadêmico referente ao primeiro semestre letivo de 2021 dos cursos de graduação da Uemasul, em virtude da situação de excepcionalidade, decorrente da pandemia. A coordenação do mestrado em Letras decidiu prorrogar o calendário do curso por seis meses, que correspondem ao período de outubro de 2021 a abril de 2022.

\section{EXPERENCIANDO ALTERNATIVAS NA EDUCAÇÃo: AULAS REMOTAS, SÍNCRONAS E ASSÍNCRONAS}

No campo educacional, após o choque inicial, com a paralisação de quase tudo, foram-se encontrando alternativas de continuidade das atividades de ensino. A Uemasul instituiu o ensino remoto, entendendo que se trata de ensino mediado por tecnologias, realizado de forma síncrona ou assíncrona (MARANHÃO, 2020b). Nesses termos, as atividades remotas são constituídas em atividades síncronas - que correspondem a um terço $(1 / 3)$ da carga horária do componente curricular -, nas quais a interação entre os participantes ocorre de forma simultânea, no espaço virtual no qual se desenvolvem e em atividades assincronas, em que a interação não ocorre de forma simultânea.

A universidade, como instituição de ensino, objetiva instrumentalizar-se a fim de atender às demandas da comunidade acadêmica, em que as tecnologias da informação e comunicação (TICs) assumiram uma função relevante em termos de instrumento pedagógico. Busca ofertar aos acadêmicos os conteúdos teórico-metodológicos, em múltiplos suportes e ambientes de aprendizagem, não restringindo o estudo apenas aos materiais impressos, pois, de certa forma, as TICs vinham sendo utilizadas pelo corpo docente, talvez de forma tímida. 
A instituição também se valia de plataformas virtuais para que professores e alunos pudessem se ambientalizar e envolver-se com esses recursos.

Para tanto, a Uemasul possui uma página eletrônica no domínio edu.br e, na página, estão hospedados os serviços de rotinas acadêmicas internas, inclusive o acesso a portais estaduais e a portais nacionais ligados à educação superior. No Sistema Integrado de Gestão de Atividades Acadêmicas (Sigaa), há acesso aos serviços da biblioteca geral da universidade, além de acesso direto a uma outra biblioteca virtual. Especificamente, oferece os serviços de chat da turma, chats agendados, notícias, fóruns, web conferência, entre outros. A Uemasul possui canal oficial no YouTube, para apresentação on-line de eventos e arquivos disponiveis para posterior pesquisa. No que concerne às competências especificas de linguagem e suas tecnologias, a BNCC (BRASIL, 2018, p. 491) ressalta que se deve possibilitar a compreensão do "funcionamento e a potencialidade dos recursos oferecidos pelas tecnologias digitais para o tratamento das Linguagens". A Uemasul, com vistas ao cumprimento da BNCC, incentiva o comprometimento dos discentes com o seu próprio desenvolvimento profissional.

Ao considerar especificamente o curso de Letras - Lingua Portuguesa e Literaturas, verifica-se que o curso propõe adotar metodologias e postura docente que permitam a construção do processo ensino-aprendizagem, a fim de estabelecer no cotidiano seu envolvimento interativo e dialógico entre teoria e prática, de forma interdisciplinar e contextualizada. Assim, conforme Stella e Puccini (2008, p. 65), "ser competente para" é mais que simplesmente "saber sobre", pois trata-se de entender que "ser competente é saber sobre (dominio cognitivo), saber fazer (domínio psicomotor) e saber ser (dominio afetivo)".

A construção do saber não se restringe ao espaço universitário, trata-se de uma prática que se desenvolve em diferentes ambientes, com atividades de forma presencial, remota - aulas sincronas e assíncronas -, ou híbrida. Para tanto, a universidade propicia espaços para orientar e instigar a prática reflexiva de construção do conhecimento científico e a socialização dos saberes discutidos ou gerados no curso de Letras - Língua Portuguesa e Literaturas. Assim sendo, González Pecotche (2013, p. 96) afirma que o docente, ao propor metodologias ativas de aprendizagem, considera o aluno "bom investigador, aquele que busca junto com o conhecimento a forma de realizar o próprio aperfeiçoamento, encontra em cada aquisição uma nova fonte de recursos que o conduzem a superar suas aptidões individuais".

Nessa perspectiva, as metodologias atuais visam propor uma aprendizagem ativa, pois essas podem ser consideradas atividades que incentivam o aluno a refletir, constantemente, acerca do que está fazendo, com acesso a diferentes fontes de informações que poderão auxiliá-lo na tarefa (BONWELL; EISON, 1991). Torna-se, portanto, fundamental a participação do docente "do processo de repensar a construção do conhecimento, na qual a mediação e a interação são os pressupostos essenciais para que ocorra aprendizagem" (BORGES; ALENCAR, 2014, p. 120).

O curso incentiva e possibilita diferentes práticas pedagógicas e uma diversidade de suportes e estratégias de ensino, de acordo com as especificidades das disciplinas e modos de oferecimento das aulas nas modalidades presencial, remota e híbrida, por meio das novas tecnologias da informação e comunicação (NTIC). As diferentes metodologias ativas vêm, também, sendo adotadas no curso, tais como: aprendizagem baseada em problemas; aprendizagem baseada em 
projetos de pesquisa e extensão universitária; aprendizagem em equipe com participação em grupos de estudo, pesquisas de campo, eventos científicos, debates; sala de aula invertida (flipped classroom), jogos ou uso de simulações, casos para ensino; aprendizagem por pares (peer instruction), entre outras (MACHADO, 2017, p. 107). Compreendendo que as TICs podem ser substituídas por inovações mais avançadas, o curso prevê alguns usos de diferentes recursos no contexto educativo:

Web no contexto educativo - Com o advento da Web 1.0, foram disponibilizados sites e portais que os usuários poderiam acessar, navegar e fazer download de conteúdo, softwares, imagens, entre outros. Já com a Web 2.0 os usuários têm maior interatividade, através de redes sociais.

Blog - é uma palavra derivada do Weblog ou "diário online". Geralmente apresenta publicações diversas com textos, imagens, vídeos e outros recursos, que podem ser de assunto específico ou não.

AVA - Ambiente Virtual de Aprendizagem - Os AVAs são ambientes que podem disponibilizar inúmeras ferramentas que propiciam a comunicação entre os participantes, bem como ferramentas de publicação de conteúdo, testes de múltipla escolha, questões dissertativas, wiki (ferramenta de construção coletiva), quiz (ferramenta on-line de avaliação), bate-papo, entre outros. Existem diferentes ambientes virtuais disponiveis na Web gratuitos, que podem ser instalados ou apenas utilizados online, como exemplo, temos o Moodle, um sistema de gerenciamento para criação de curso online. O EDMODO é uma plataforma para o gerenciamento da aprendizagem, desenvolvido e disponibilizado na nuvem.

Editor on-line compartilhado - A edição on-line compartilhada é uma ferramenta que permite o acesso simultâneo de vários usuários na confecção de documentos, textos, apresentação de slides, planilha eletrônica, entre outros. Existem diferentes ferramentas disponiveis na Web, como por exemplo, o GoogleDocs (disponivel com acesso ao drive ferramenta do Google) e o OneDrive (disponível no site da Microsoft). Estas ferramentas são muito úteis na criação e edição de diferentes tipos de documentos, com fácil acesso e uso gratuito. Estão disponíveis no Drive, aplicativo da conta do Gmail/Google que permite criação, edição, publicação de documentos: Documentos Google, Apresentações Google, Planilhas Google, Desenhos Google, Google My Maps, e Google sites.

Ferramentas de comunicação - Outras ferramentas da Web são muito utilizadas e agregam imenso valor às atividades. São elas: ferramentas de comunicação e interação, correio eletrônico (e-mail), listas e-mails, ferramentas de comunicação instantânea (chat, Messenger), fóruns e grupos de discussão e videoconferência.

Vídeo sob demanda ou on demand - Este tipo de serviço possibilita ao usuário postar, compartilhar e acessar vídeos na Web. É um serviço interativo pois possibilita ao usuário pesquisar e escolher um vídeo, a partir de uma relação disponível, assisti-lo no momento que desejar e tendo controle, podendo pausar, adiantar ou retroceder o vídeo. O Youtube tem grande potencial na educação, tendo em vista que estão disponíveis vídeos de diferentes autores, com diferentes assuntos, além de permitir ao usuário postar os seus vídeos. Os vídeos podem ser usados antes, durante ou depois da aula, como inspiração, auxiliar na explicação, ou para postagem de atividades em vídeos criados pelos alunos. O Porta Curtas <http://portacurtas.org.br> é um site que disponibiliza mais de 11 mil filmes curta metragem, de variados assuntos. Disponibiliza filmes apre- 
sentados em diferentes festivais de cinema brasileiros. Outro serviço de vídeo sob demanda é o Vimeo <http:/ / vimeo.com. br> com uma grande variedade de vídeos.

Podcast - é uma gravação de áudio, de qualquer origem (programa de rádio, leitura de texto, gravação de áudio livre, ou conversão de vídeo em áudio). O áudio é disponibilizado na Web para download para ser reproduzido como um MP3 [...]. Audiobook - Apresenta-se disponível através de diferentes ferramentas online ou off-line e disponibilizam a locução de livros gravados em arquivos de áudio digital.

Animação - Animações podem ser entendidas como imagens dinâmicas, criadas por computador, ou a partir de vídeos, que permitem interação do usuário com avanço e retrocesso de imagens [...].

Realidade virtual - A realidade virtual é gerada por computador, através de softwares criam ambientes interativos em que o usuário pode controlar tridimensionalmente, trazendo a sensação de estar inserido neste mundo criado (MACHADO, 2017, p. 110-114).

Nas metodologias ativas, o uso de recursos não é prática obrigatória, todavia, propicia grande auxílio, pois o que faz a diferença é a organização da atividade, sendo basilar para o processo de ensino-aprendizagem em sala de aula, seja esse ambiente físico ou virtual.

Essas normas da graduação não atingem, quanto ao calendário, o PPGLe stricto sensu, mestrado em Letras, contudo, as providências de adoção do ensino remoto foram assumidas pela coordenação. Como o início do curso se deu no meio do semestre de 2019, o calendário foi elaborado de forma que todas as atividades previstas para o primeiro semestre fossem contempladas. Assim, o primeiro e o segundo semestres da primeira turma do programa foram concluídos no tempo previsto. Porém, com a pandemia, houve atraso na preparação para a qualificação. Dessa forma, fez-se necessária a prorrogação do prazo inicialmente previsto para cumprimento do calendário inicial (MARANHÃO, 2021b). Mesmo assim, os trabalhos dos pós-graduandos, a dissertação e a produção técnico-tecnológica, encontram-se em andamento, para a qualificação e defesa, previstas para 2021.

Para o ingresso da segunda turma, devido à pandemia, o edital foi suspenso, mas, no fim do primeiro semestre de 2020, foi possivel reabri-lo, com a consequente mudança/prorrogação das datas para a seleção, que ocorreu de forma remota. As atividades acadêmicas foram iniciadas em novembro de 2020 , e a forma que surgiu como a mais viável, também, foi o ensino remoto. Essa possibilidade implicou o uso de estratégias que não eram familiares a muitos docentes, principalmente a preparação de material que auxiliasse nas aulas, na mediação do conhecimento, como o uso de podcasts (os tradicionais, somente com som, e os renovados, com imagem e som), fanfics (as tradicionais ou como adaptação do exercício de construção com reescrituras de conteúdo, por exemplo), vídeos (possibilidades inúmeras de apresentação/propostas de abordagens de determinado conteúdo, por meio de documentários, videoaulas, curtas e médias-metragens), experimentos de criação artística (por exemplo, recriação das antigas radionovelas como forma de "ficcionalização" de conteúdos, temáticas etc.), preparação de slides com gravação de voz, uso do cinema, da fotografia, da música, das artes plásticas, entre outros. 
Em se tratando de educação formal, sabe-se que, em sua trajetória, o ensino teve como sustentação a transmissão oral e escrita do conhecimento, de tal maneira que, mesmo com passar dos tempos, comumente, outras possibilidades de abordagens/usos sempre foram negligenciadas (GIL, 2015). A escrita consolidou-se, a partir das ideias positivistas cristalizadas no século XIX, como receptáculo legítimo e inquestionável do saber (BANNELL, 2016). Ao professor, coube o papel solitário e igualmente incontestável de propagador das informações, e quanto ao aluno, buscou-se o espectador passivo, sem reflexão, discussão e/ou participação na construção do conhecimento. Contraditoriamente a isso, no último século, surgiram novas tecnologias, meios de comunicação e expressões artísticas que inseriram novas formas de leitura e representação do real no cotidiano da sociedade, implicando uma mudança não apenas comportamental, mas de ações como um todo (SILVA; GOMES, 2015). Uma dessas ações encontra-se no processo de inserção de novas mídias - vistas na perspectiva da união e do desdobramento de novas tecnologias e métodos de comunicação -, e do uso da arte em sala de aula. Segundo Almeida (2000, p. 12),

Essas transformações tecnológicas atuais abrem perspectivas de mudanças fundamentalmente no campo educacional, impondo assim um grande desafio para educadores e educandos. Historicamente, o campo da educação é extremamente complexo e resistente às mudanças de qualquer ordem, exigindo múltiplas ações que provocam um impacto significativo na qualidade da formação e da prática docente.

Desse modo, é urgente o debruçar-se sobre essa questão, no intuito de fazer reflexões e construir proposições e metodologias acerca das novas tecnologias, meios de expressões/comunicações e produções artísticas, de suas linguagens e de suas dimensões pedagógicas, visto que a inclusão desses estudos e o compartilhamento de experiências, nos diferentes niveis de ensino, tornam-se uma medida necessária para uma formação integral do estudante. Além disso, as metodologias devem ser consonantes às características culturais das sociedades modernas, nas quais o fenômeno comunicativo global assume grande importância social, cultural e ideológica.

Nesse contexto, urge a necessidade de mudança no ensino, uma vez que as novas mídias/plataformas/tecnologias (a exemplo da internet, YouTube, streaming, celular, tablet, notebook, entre outros) e expressões artísticas (cinema, música etc.) integram-se perfeitamente como necessários estudos e práticas pedagógicas. Elas possibilitam a aquisição de conhecimentos e de reflexão crítica sobre uma faceta preponderante da nossa história cultural recente, ou seja, desses últimos cem anos em que a humanidade tem deixado as suas marcas narrativas e multiculturais em palavras, imagens e sons interligados de várias formas, de tal maneira que os conhecimentos transmitidos pelas produções dos novos veículos/plataformas/redes de comunicação, pelas expressões artísticas e pela inserção de novas tecnologias, constituem aquilo que alguns autores têm chamado de um autêntico currículo paralelo. É certo que, para dirimir as implicações pedagógicas, faz-se necessário conhecer, reconhecer, estudar e investigar no próprio âmbito escolar, uma vez que esses novos recursos interferem no processo normal de ensino-aprendizagem. E as implicações pedagógicas devem ocorrer tanto no que diz respeito aos efeitos cognitivos mais específicos quanto no 
tocante à esfera mais global dos valores, das atitudes e dos padrões de comportamento e ideologias.

Ademais, a utilização desses recursos no ensino suscita discussões incessantes. A principal delas se organiza em torno da utilização crítica das palavras, imagens, sons e sua validade no processo de aprendizagem. Assim, a televisão e a internet, como meios de comunicação e entretenimento; o celular, o computador, entre outros, como instrumentais de novas tecnologias; o cinema, as fanfics, podcasts etc., como expressões artísticas/de comunicação, com consumo/expressão cada vez mais intenso, motivam críticas e debates sobre o uso mais correto das informações difundidas num ritmo cada vez mais frenético. Desse modo, cabe estabelecer uma premissa básica para transformar a experiência social e cultural das novas tecnologias, meios de comunicação e produções artísticas, que começa antes e vai além da sala de aula, em uma experiência de conhecimento escolar, pois toda produção humana de comunicação tecnológica e/ou artística é resultado de um conjunto de seleções, escolhas, recortes e perspectivas, que envolve um leque de profissionais e de interesses comerciais, ideológicos e estéticos.

Nesse cenário, uma das experiências que está sendo realizada e que pode ser considerada inovadora é a articulação entre o mestrado e a comunidade acadêmica, com alunos das licenciaturas, especialmente dos cursos de Letras e de Pedagogia, bem como com a comunidade. Essas atividades proporcionam a esses alunos a participação em seminários realizados pelos pós-graduandos, coordenados pelos professores do programa, por exemplo, o Seminário de Sociolinguística, a XV Jornada de Linguística e Filologia da Língua Portuguesa, no polo Imperatriz. As atividades são relativas a temáticas próprias e obrigatórias aos mestrandos e fundamentais também para os alunos das licenciaturas. A participação/resposta massiva da comunidade acadêmica e a experiência está sendo muito significativa em função da natureza do programa, que é o de contribuir para o desenvolvimento da área educacional, capacitando profissionais para uma ação transformadora em educação. O PPGLe, também, possui uma página eletrônica no domínio edu.br, em construção, na qual estão hospedados atos normativos e acesso ao conteúdo integral da página eletrônica da Uemasul.

A prática do ensino remoto possibilitou ao programa, em ação também inovadora, criar o projeto "De Conversa em Conversa", no qual, em todas as disciplinas ministradas no mestrado em Letras, são convidados professores de diversas IES com outros programas nacionais e internacionais para ministrarem conferências, palestras, debates acerca de temáticas diversas que dialogam com a natureza/objetivos do programa. Conversas ora restritas aos pós-graduandos, ora, na sua maioria, acessivel aos acadêmicos da Uemasul e à comunidade interessada. Com isso, o programa estabelece diálogos amplos com um grande número de pessoas, estreita laços entre professores do programa com professores de outras instituições e dá visibilidade às pesquisas e às ações do mestrado. Essa possibilidade de ter tido, de forma remota, convidados nacionais e aulas com professores de outras universidades faz parte dessas ações relevantes de regionalização e, futuramente, de internacionalização. Há um impacto social e cultural em atividades colaborativas porque possibilitam a compreensão de fenômenos educacionais de outras regiões, de outros países.

A criação do primeiro programa de pós-graduação stricto sensu da Uemasul permitiu identificar, já além do que identificado na graduação, novos contextos 
e outras necessidades acerca das ações em processos de formação de professores. Assim, percebe-se que está se iniciando a construção de um acervo conceitual e teórico, bem como de fundamento de dados e compreensão das realidades locais. Nesse contexto, propõe-se uma discussão, com certa urgência, sobre a criação do Laboratório de Linguagem, Língua e Literatura (LALLit) do PPGLe, que possibilitará, ainda mais, cumprir o seu papel de formar profissionais e pesquisadores para uma ação transformadora em educação, com foco em sua qualificação nos âmbitos da docência e da ação técnico-científica. As ações devem ser de forma que impactem os contextos de inserção profissional dos sujeitos envolvidos na educação, objetivando torná-los mais letrados para o uso das novas mídias e produções artísticas como recursos pedagógicos no processo de ensino-aprendizagem e, consequentemente, para o desenvolvimento de todos os membros participantes - algo sugerido pelas próprias diretrizes educacionais (BRASIL, 2018), por exemplo.

A relevância de implantação do laboratório se dá por ele possibilitar o efetivo diálogo da/na instituição com diversos atores (professores, mestrandos, acadêmicos da graduação e egressos) sendo, portanto, um espaço multiusuário, bem como multidisciplinar por agregar vários campos do conhecimento, como História, Geografia, Pedagogia, mas, principalmente os de Letras e, assim, sedimentar o desenvolvimento da pesquisa das licenciaturas na Uemasul. O LALLit será, também, espaço agregador de inúmeras pesquisas, experimentos, exercícios, produções novas e que estão em curso e outras tantas que, tendo o laboratório como instrumento impulsionador, serão iniciadas e continuadas; e será utilizado pelo PPGLe para qualificação e defesa das dissertações dos mestrandos.

\section{CONSIDERAÇÕES FINAIS}

A Uemasul, atenta aos dias dificeis que vimos enfrentando, com o propósito de atender à comunidade acadêmica acerca de suas principais demandas formativas com base na experiência do ensino remoto, tais como as aulas remotas síncronas, desenvolvimento de projetos pesquisa e projetos extensão, disponibiliza aos docentes e discentes a entrega de chips SIM cards, referentes ao Auxílio Emergencial de Inclusão Digital dos campi Imperatriz, Açailândia e Estreito.

Desse modo, as TDIC têm sido incorporadas às práticas docentes como meio para promover aprendizagens mais significativas, sendo fundamental na implementação de metodologias de ensino ativas, alinhando o processo de ensino-aprendizagem à realidade dos estudantes. Por conseguinte, as universidades, principalmente em seus programas de pós-graduação stricto sensu, em sua atribuição de desenvolverem pesquisas, estudos e inovação, não podem se furtar de problematizar a produção e sua relação com o ensino, atentas na proposição de diálogo constante com a comunidade.

\section{IN SEARCH OF ALTERNATIVES IN EDUCATION IN HIGHER EDUCATION INSTITUTION: REMOTE, SYNCHRONOUS AND ASYNCHRONOUS CLASSES}

Abstract: This article proposes reflections on the course of Portuguese language teaching and its literatures carried out during the pandemic period in a public higher education institution. The objective is to present the trajectory of an un- 
dergraduate program in Linguistics and Literature and a master's program in Linguistics and Literature, based on some normative acts to face the Covid-19 pandemic in Maranhão. This discussion is accompanied by a brief case study that aims to illustrate the theoretical-methodological considerations presented. Thus, it is pointed out how the teaching process seeks innovative practices, like active methodologies, in the dissemination of knowledge about language and literature.

Keywords: Portuguese Language and Literature. Covid-19 pandemic. Active methodologies. Maranhão. Remote teaching.

\section{REFERÊNCIAS}

ALMEIDA, M. E. de. Informática e formação de professores. Brasília: Ministério da Educação, 2000.

BANNELL, R. I. (org.). Educação no século XXI: cognição, tecnologia e aprendizagem. São Paulo: Vozes, 2016.

BONWELL, C. C.; EISON, J. A. Active learning: creating excitement in the classroom. Washington, DC: Eric Digests, 1991. Publication Identifier ED340272. Disponivel em: http://www.eric.ed.gov/PDFS/ED340272.pdf. Acesso em: 17 jul. 2020.

BORGES, T. S.; ALENCAR, G. Metodologias ativas na promoção da formação crítica do estudante: o uso das metodologias ativas como recurso didático na formação crítica do estudante do ensino superior. Cairu em Revista, ano 3, n. 4, p. 119-143, 2014.

BRASIL. Lei ${ }^{\circ}$ 9.394, de 20 de dezembro de 1996. Estabelece as diretrizes e bases da educação nacional. Brasília: Presidência da República, 1996. Disponível em: http://www.planalto.gov.br/ccivil_03/leis/19394.htm. Acesso em: 10 dez. 2020.

BRASIL. Ministério da Educação. Base Nacional Comum Curricular. Brasília: Ministério da Educação, 2018. Disponível em: http:/ / basenacionalcomum.mec. gov.br/. Acesso em: 20 maio 2021.

BRASIL. Decreto Legislativo $n^{\circ}$ 6, de 2020. Reconhece, para os fins do art. 65 da Lei Complementar $n^{\circ} 101$, de 4 de maio de 2000, a ocorrência do estado de calamidade pública, nos termos da solicitação do Presidente da República encaminhada por meio da Mensagem n 93, de 18 de março de 2020. Brasília: Congresso Nacional, 2020a. Disponivel em: http://www.planalto.gov.br/ccivil_03/Portaria/DLG6-2020.htm. Acesso em: 20 abr. 2021.

BRASIL. Ministério da Educação. Parecer CNE/CP $n^{\circ}$ 5/2020. Ministério da Educação. Reorganização do Calendário Escolar e da possibilidade de cômputo de atividades não presenciais para fins de cumprimento da carga horária mínima anual, em razão da Pandemia da COVID-19. Diário Oficial da União, seção 1, Brasília, DF, p. 32, $1^{\circ}$ jun. 2020b. Disponível em: http://portal.mec.gov.br/ index.php?option $=$ com_docman \&view $=$ download\&alias $=14511-$ pcp005-20\&category_slud=marco-2020-pdf\&Itemid=30192. Acesso em: 29 abr. 2021. 
GIL, A. C. Didática do ensino superior. São Paulo: Atlas, 2015.

GONZÁLEZ PECOTCHE, C. B. Logosofia: ciência e método: técnica da formação individual consciente. 12. ed. São Paulo: Logosófica, 2013.

MACHADO, A. de B. et al. Práticas inovadoras em metodologias ativas. Florianópolis: Contexto Digital, 2017.

MARANHÃO. Lei $n^{\circ}$ 4.400, de 30 de dezembro de 1981. Cria a Universidade Estadual do Maranhão. São Luís: Governo do Estado do Maranhão, 1981. Disponivel em: https://www.uema.br/wp-content/uploads/2015/01/estatuto.pdf. Acesso em: 6 abr. 2021.

MARANHÃO. Lei $n^{\circ}$ 5.921, de 15 de março de 1994. Reorganiza a Universidade Estadual do Maranhão. São Luís: Governo do Estado do Maranhão, 1994. Disponivel em: https://www.uema.br/wp-content/uploads/2015/01/estatuto. pdf. Acesso em: 3 fev. 2021.

MARANHÃO. Lei $n^{\circ} 10.525$, de 3 de novembro de 2016. Dispõe sobre a área de atuação da Universidade Estadual da Região Tocantina do Maranhão - UEMASUL, nos termos do art. $1^{\circ}$ da Lei $\mathrm{n}^{\circ} 10.525$, de 3 de novembro de 2016. São Luís: Governo do Estado do Maranhão, 2016a. Disponivel em: http:/ / stc.ma.gov. br/legisla-documento/?id=4522. Acesso em: 6 dez. 2019.

MARANHÃO. Projeto de Lei $N^{\circ} 181 / 2016$. Dispõe sobre a criação da Universidade Estadual da Região Tocantina do Maranhão - UEMASUL, com sede na cidade de Imperatriz. São Luís: Governo do Estado do Maranhão, 2016b. Disponivel em: http: / / sapl.al.ma.leg.br:8080/sapl/consultas/materia/materia_mostrar_ proc?cod_materia=8360. Acesso em: 24 jan. 2020.

MARANHÃO. Plano de Desenvolvimento Institucional - PDI: 2017-2021, Imperatriz, MA: Universidade Estadual da Região Tocantina do Maranhão, 2017. Disponivel em: https://www.uemasul.edu.br/portal/institucional/pdi/. Acesso em: 20 mar. 2021.

MARANHÃO. Decreto $N^{\circ}$ 35.662, de 16 de março de 2020. Dispõe sobre a suspensão, por 15 dias, das aulas presenciais nas unidades de ensino da rede estadual de educação, do Instituto Estadual de Educação, Ciência e Tecnologia do Maranhão - IEMA, da Universidade Estadual do Maranhão - UEMA e da Universidade Estadual da Região Tocantina do Maranhão - UEMASUL, nas instituições de ensino das redes municipais e nas escolas e instituições de ensino superior da rede privada localizadas no Estado do Maranhão. Diário Oficial do Estado do Maranhão, São Luís, 16 mar. 2020a. Disponível em: https: //www. legisweb.com.br/legislacao/?id=390834\#: :text=1\%C2\%BA\%20Ficam\%20 suspensas\%2C\%20por\%2015,Art. Acesso em: 15 jan. 2021.

MARANHÃO. Resolução $n^{\circ}$ 108/2020 CONSUN/UEMASUL, de 7 agosto de 2020. Estabelece diretrizes e normas para o ensino emergencial remoto e demais atividades de pesquisa e extensão, durante a suspensão das atividades presenciais, e altera o Calendário Acadêmico 2020 em virtude da situação de excepcionalidade decorrente da pandemia do novo coronavírus (SARS-CoV-2), na UEMASUL. Imperatriz: Universidade Estadual da Região Tocantina do Maranhão, 2020b. Disponivel em: https://www.uemasul.edu.br/portal/wp-content/uploads/2020/12/resolucao_108-2020_consun_uemasul.pdf. Acesso em: 20 mar. 2021. 
MARANHÃO. Instrução Normativa $N^{\circ}$ 01/2021-GR/UEMASUL, de 08 de fevereiro de 2021. Atualizar orientação relativas às medidas de prevenção e precaução para enfrentamento da emergência de saúde pública de importância internacional decorrente da pandemia Covid-19. Imperatriz, MA: Universidade Estadual da Região Tocantina do Maranhão, 2021a. Disponivel em: https://www.uemasul.edu.br/portal/wp-content/uploads / 2021 / 02 / 2instrucao_normativa_01-2021_GR-UEMASUL.pdf. Acesso em: 20 mar. 2021.

MARANHÃO. Instrução Normativa $N^{\circ}$ 01/2021-PPGLe/UEMASUL, de 08 de março de 2021. Imperatriz, MA: Universidade Estadual da Região Tocantina do Maranhão, 2021b. Disponivel em: http://www.uemasul.edu.br/portal/ publicacoes/?pg=9?. Acesso em: 20 maio 2021.

MARANHÃO. Instrução Normativa $N^{\circ}$ 02/2021-GR/UEMASUL, de 01 de março de 2021. Atualizar orientação relativas às medidas de prevenção e precaução para enfrentamento da emergência de saúde pública de importância internacional decorrente da pandemia Covid-19. Imperatriz, MA: Universidade Estadual da Região Tocantina do Maranhão, 2021c. Disponivel em: http://www.uemasul.edu.br/portal/publicacoes/?pg=8. Acesso em: 20 abr. 2021.

MARANHÃO. Instrução Normativa No 07/2021-GR/UEMASUL, de 04 de abril de 2021. Altera a Instrução Normativa $n^{\circ}$ 03/2021-GR/UEMASUL, atualizando orientações relativas às medidas de prevenção da emergência de saúde pública de importância internacional decorrente da pandemia Covid-19. Imperatriz, MA: Universidade Estadual da Região Tocantina do Maranhão, 2021d. Disponível em: http://www.uemasul.edu.br/portal/publicacoes/?pg=8. Acesso em: 20 abr. 2021.

MARANHÃO. Instrução Normativa No 08/2021-GR/UEMASUL, de 11 de abril de 2021. Atualizar orientações relativas às medidas de prevenção e precaução para enfrentamento da emergência de saúde pública de importância internacional, decorrente da pandemia Covid-19. Imperatriz, MA: Universidade Estadual da Região Tocantina do Maranhão, 2021e. Disponivel em: https://www.uemasul.edu.br/portal/. Acesso em: 20 abr. 2021.

SILVA, S. M. O. C. da; GOMES, F. C. G. Tecnologias e mídias digitais no contexto escolar: uma análise sobre a percepção dos professores. In: CONGRESSO NACIONAL DE EDUCAÇÃO - EDUCERE, 12., 2015, Curitiba. Anais [...]. Curitiba: Pontifícia Universidade Católica do Paraná, 2015.

STELLA, R. C. R.; PUCCINI, R. F. A formação profissional no contexto das Diretrizes Curriculares Nacionais para o curso de medicina. In: PUCCINI, R. F.; SAMPAIO, L. O.; BATISTA, N. A. (org.). A formação médica na Unifesp: excelência e compromisso social. São Paulo: Editora Unifesp, 2008. 